\title{
Proton Irradiation Creep in Pyrocarbon
}

Gary S. Was

Anne Campbell

October 2011

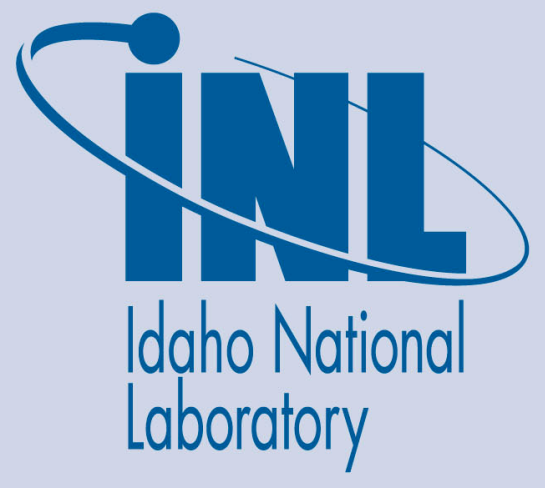

The INL is a U.S. Department of Energy National Laboratory operated by Battelle Energy Alliance 
INL/EXT-15-35291

\section{Proton Irradiation Creep in Pyrocarbon}

${ }^{1}$ University of Michigan

\author{
Gary Was ${ }^{1}$ \\ Anne Campbell
}

October 2011

Prepared for the

U.S. Department of Energy

Office of Nuclear Energy

Under DOE Idaho Operations Office

Contract DE-AC07-05ID14517 


\section{FINAL REPORT}

Project Title: $\quad$ Proton Irradiation Creep in Pyrocarbon

Project No. 238741

Covering Period: September 3, 2010 through September 30, 2011

Date of Report: $\quad$ October 3, 2011

Recipient: $\quad$ University of Michigan

2355 Bonisteel Blvd

Ann Arbor, MI 48109-2104

Award Number: DE-AC07-05ID14517

Principal

Investigator:

Gary S. Was, 734 763-4675, gsw@umich.edu

Graduate student: Anne Campbell

Project Objective: This project aims to understand how irradiation creep in pyrocarbon using proton irradiation under controlled stresses and temperatures. Experiments will be conducted over a range of temperatures and stresses per the proposal submitted. The work scope will include the preparation of samples, measurement of deposition thickness, thickness uniformity, and anisotropy. The samples produced will be made in strips, which will be used for the creep experiments. Materials used will include pyrolytic carbon (PyC), Highly Oriented Pyrolytic Graphite (HOPG), or graphite strip samples in that order depending upon success. Temperatures tested under will range from $800^{\circ} \mathrm{C}$ to $1200^{\circ} \mathrm{C}$, and stresses from $6 \mathrm{MPa}$ to $20.7 \mathrm{MPa}$. Optional testing may occur at $900^{\circ} \mathrm{C}$ and $1100^{\circ} \mathrm{C}$ and stresses from $6 \mathrm{MPa}$ to $20.7 \mathrm{MPa}$ if funding is available. 
Introduction

This report provides a summary of the work completed in the study of proton irradiation induced creep behavior of pyrolytic carbon. The report focuses on irradiation creep experiments conducted on graphite samples while awaiting preparation of pyrocarbon strip samples that are fabricated at Oak Ridge National Laboratory. The research performed thus far has shown that the proton irradiation induced creep is predominately occurring in the secondary creep regime. Also observed for the graphite samples is the linear dependence of the apparent creep rate on the applied stress.

\section{Graphite Samples for Irradiation Creep Behavior}

Since pyrocabon samples were not available at the start of this project, it was decided that initial irradiation creep experiments would be conducted on graphite samples having microstructure as similar to pyrocarbon as achievable. The primary difference between the microstructures of pyrocarbon and graphite is the macroscopic structures. In pyrocarbon, macroscopic structures are formed in the gas phase, which are then deposited onto the substrate. These macroscopic structures are best described as $0.5-1.0 \mu \mathrm{m}$ spheroids with small (few nm diameter) carbon clusters at the center with concentric spherical shells (similar to the layers of an onion) of graphite-style basal planes encompassing the clusters. In graphite the macroscopic structure is that of graphite grains, which have the hexagonal crystal structure. A graphite grade was chosen that has an average grain size of $<1 \mu \mathrm{m}$, which is similar to the macroscopic structure size in pyrocarbon. The graphite grade selected was ZXF-5Q available from POCO Graphite Inc. This grade has an average grain size of $<1 \mu \mathrm{m}$ and a density of $1.78 \mathrm{~g} / \mathrm{cm}^{3}[1]$. The samples are machined from a block of graphite using electrical discharge machining (EDM).

\section{Modifications to Proton Irradiation Creep System}

The proton irradiation creep system utilizes a Laser Speckle Extensometer (LSE) to measure the dimensional change of the samples during the creep experiments. The original system utilized a green laser and filter to allow for high temperature applications. During preliminary irradiation creep experiments it was found that at temperatures above $900^{\circ} \mathrm{C}$, the image from the video camera became saturated and resulted in the inability of the computer software to track and calculate dimensional change.

Discussion with Jay Jellison, from Oak Ridge National Laboratory, led to the hypothesis that the graphite was behaving as a black-body emitter at temperatures above $900^{\circ} \mathrm{C}$ and that this emission was occurring in the same wavelength region as the green laser. The emission spectrum decreases rapidly at shorter wavelengths so it was determined that changing from a green laser at $510 \mathrm{~nm}$ to a violet laser and filter at $405 \mathrm{~nm}$ should alleviate video camera saturation. An experiment was performed at temperatures from $900^{\circ} \mathrm{C}$ to $1250^{\circ} \mathrm{C}$ to test for LSE saturation with the violet laser and filter for the LSE. Over this entire temperature range, no saturation of the video camera was observed. This change will allow for the creep experiments to be performed over a temperature range $\left(900^{\circ} \mathrm{C}-1200^{\circ} \mathrm{C}\right)$ that is comparable to the temperature range the pyrocarbon layers of the TRISO fuel will experience in the reactor. 
Proton Irradiation Induced Creep Experiments

Four proton irradiation induced creep experiments were performed. The first experiment was conducted to determine if primary creep is observed in these experiments. The other experiments were performed to determine the dependence of the apparent creep rate on the applied tensile stress.

The first experiment was performed at $1000^{\circ} \mathrm{C}$, with a $20 \mathrm{MPa}$ applied stress, and a dose rate of $0.10 \mathrm{dpa} /$ day to a final dose of $1.213 \mathrm{dpa}$. The motivation for this experiment was to determine if the primary creep regime is observed with proton irradiation. Graphite undergoing neutron irradiation induced creep transitions from primary to secondary regime at doses below $0.68 \mathrm{dpa}$ with a total strain equivalent to one elastic strain unit (esu), which is defined as applied stress divided by initial Young's modulus [2]. The raw experimental data for this experiment is presented in Figure 1, which shows the sample strain measured by LSE (red), the reference sample strain measured by LSE (blue), the sample strain measured by LVDT (green), sample temperature (black), and stage current (pink). A summary of the creep rates for the different time windows is presented in Table 1. The data from this experiment shows that creep transitions from primary to secondary at doses much lower than the 0.68dpa observed for neutron irradiation. If the transition from primary to secondary creep regime is occurring the creep rate would initially be large and would continuously decrease until stabilizing in the secondary (steady state) regime. This trend was not observed with this experiment; instead the creep rate remains constant throughout. If the sample is undergoing primary creep, a rapid decrease of creep rate should be observed from the start of the irradiation until about 1 esu is obtained for the sample, which is equivalent to $20 \mathrm{MPa} / 14.5 \mathrm{GPa}=0.138 \%$, and is obtained after just three hours of irradiation for this experiment. The measured strain of the stressed sample does not show any deviation from linear in the first three hours of the irradiation.

The first experiment shows that the proton irradiation creep experiments transition early in the experiment from primary to secondary creep regime. With this result, it was determined that the minimum dose needed to investigate the effects of irradiation parameters need only be $0.1 \mathrm{dpa}$, instead of the minimum dose of $0.68 \mathrm{dpa}$ for neutron irradiation. The next experiments were performed at a constant temperature of $1000^{\circ} \mathrm{C}$ and dose rate of $0.100 \mathrm{dpa} / \mathrm{day}$. The parameter that was altered was the applied tensile stress ranging from $10 \mathrm{MPa}-40 \mathrm{MPa}$, with $20 \mathrm{MPa}$ serving as the reference condition. The experimental data for three different applied stress conditions are presented in Figure 2 for 20MPa, Figure 3 from 40MPa, and Figure 4 for 10MPa. In each figure the raw experimental data shows the sample strain measured by LSE (red), the reference sample strain measured by LSE (blue), the sample strain measured by LVDT (green), true sample strain calculated from the LSE strain and reference measurements (light blue), sample temperature (black), and stage current (pink), along with creep rates determined by linear fit. The true strain in the stressed sample is calculated by subtracting the instantaneous strain of the reference sample from the instantaneously strain of the stressed sample. The strain in the stressed sample as measured using either the LSE or LVDT is referred to as the apparent strain.

There are some significant features of the raw data presented in Figure 2Figure 4 that should be noted. The first is the stability of the data throughout the experiment. The stage current was held stable, which is reflected in the temperature stability. The strain measurements from the LSE and LVDT were analyzed with linear curve fit which included the $95 \%$ confidence for the 
slope. For all the fits, the $95 \%$ confidence interval for the slope was at least two orders of magnitude smaller than the slope, but most were three orders of magnitude smaller. For the data presented in Figure 2 the apparent creep rates from the LSE and LVDT agree within 3\%, but unexpectedly the reference sample shows significant elongation rather than the expected contraction. For the data presented in Figure 3, the apparent creep rates from the LSE and LVDT agree within $10 \%$ and the reference sample, which was held over from the first experiment shows the expected contraction. For the data presented in Figure 4, the apparent creep rates agree within $4 \%$, but again like the first experiment the reference sample, which was the same sample from the first two experiments, shows elongation.

The effect of applied stress on the apparent creep rate for the stressed sample can be determined from the results of these experiments. The applied stress and apparent creep rate values from the LSE and LVDT tabulated in Table 2. Table 3 summarizes the results for the different linear fit permutations that were performed to determine the applied stress dependence. The primary division was to perform a linear fit on the LSE and LVDT data separately, and second to include and exclude the data from the experiment presented in Figure 1. The data presented in Figure 1 are noticeably less stable than the other experiments, thus those values will be excluded from the analysis. The maximum difference in creep rates from the LSE and LVDT is $<10 \%$ thus the linear fit of the combined data will used for the final dependence. Figure 5 is a plot of the apparent creep rates from both the LSE (in red) and the LVDT (in blue) versus applied stress, along with the linear fit of the combined data without the inclusions of the rates from Figure 1.

The linear dependence of LSE and LVDT apparent creep rate on applied stress is:

$$
\dot{\varepsilon}\left(s^{-1}\right)=3.31 \times 10^{-9} \sigma(M P a)+8.08 \times 0^{-9} .
$$

The slope from this linear fit is the steady state creep rate coefficient, with units of ( $\left.\mathrm{s}^{*} \mathrm{MPa}\right)^{-1}$. The linear dependence of creep rate on applied stress has been observed at $900^{\circ} \mathrm{C}$ in $\mathrm{H}-451$ graphite, with a steady state creep coefficient of $4.92 \times 10^{-31} \% /\left(\mathrm{n} / \mathrm{cm}^{2} * \mathrm{~Pa}\right)$ [2]. The H-451 steady state creep coefficient can be converted into the $\left(\mathrm{s}^{*} \mathrm{MPa}\right)^{-1}$ units using the conversion:

$$
k\left(s^{*} M P a\right)^{-1}=\mathcal{K}\left(\frac{\%}{\frac{n}{c m^{2}} * P a}\right) \frac{1 \times 10^{22} \frac{n}{c m^{2}}}{6.8 d p a} d\left(\frac{d p a}{d a y}\right) * \frac{1 d a y}{86400 s} * \frac{10^{6} P a}{M P a} .
$$

This conversion results in a steady state creep rate coefficient for $\mathrm{H}-451$ graphite at $900^{\circ} \mathrm{C}$ of $8.37 \times 10^{-11}\left(\mathrm{~s}^{*} \mathrm{MPa}\right)^{-1}$, which is two orders of magnitude smaller than the value determined from these experiments. Besides the difference in the irradiation particle, the temperatures of the two experiments are different, which is significant because the temperature dependence of the steady state creep rate for graphite at temperatures above $600^{\circ} \mathrm{C}$ are not well defined. Finally, the H-451 has much larger grains than the graphite being used and it has been noticed that no two graphite grades have the same creep rate coefficient.

The apparent creep rates were used for this analysis because there was unexpected behavior of the reference sample. Instead of contracting, elongation was measured in the first experiment. To determine if this was reproducible, the same reference sample was used in the second experiment, which showed contraction. When the same sample was used for the third experiment contraction was expected but instead elongation was observed. This result indicates that the reference sample creep measurement is not reproducible. However, since all three 
experiments were performed at the same temperature and dose rate, a reference sample is not needed to make a comparison between these three experiments. Any contraction or elongation will merely cause of offset in the creep rate vs. stress curve, with no change in slope.

The unexpected behavior of the reference sample was investigated after the experiments. It was determined that there was residual stress present in the as-received, machined samples stemming from the EDM machining process. The residual stress appeared as a small curvature in the sample. But due to the small contraction expected and with the reference sample dimensional changes measured only with the LSE, the relaxation of any residual stress will flatten the sample and appear as elongation. To relax out the residual stress the samples were annealed for $24 \mathrm{~h}$ at $900^{\circ} \mathrm{C}$. After annealing the pre-anneal curvature was not observed in the samples.

An irradiation was performed on one of the annealed samples, at $900^{\circ} \mathrm{C}$ and $0.056 \mathrm{dpa} / \mathrm{day}$ to determine if the anneal removed the residual stress. The temperature and dose rate were selected from one of the proof-of-concept experiments performed on a different graphite grade, which showed noticeable contraction of the reference sample. The raw data from this experiment is presented in Figure 6, where two LSE dimensional change measurements were taken on the sample (red and blue) and the average of the two measurements (green), sample temperature (black), and stage current (pink). The LSE measured elongation on the left side and contraction on the right side of the same sample, but both rates are only a factor of 2 larger than the noise that in the LSE measurement. The combination of simultaneous elongation and contraction are most likely due to the sample twisting during the irradiation. A minor adjustment was made to the irradiation stage to inhibit twisting of the reference sample for future experiments.

\section{Pyrocarbon Sample Fabrication}

A methodology for producing pyrocarbon samples was developed in the months prior to the start of this project. The methodology was developed in conjunction with John Hunn, James Miller, Brian Jolly, and Elliott Fray of the Nuclear Fuel Materials Group at Oak Ridge National Laboratory. The development was required because pyrocarbon samples of the size and shape required for irradiation creep experiments had never been produced before. The required sample geometry is a strip $3 \mathrm{~mm}$ wide, $70 \mu \mathrm{m}$ thick, and a minimum of $25 \mathrm{~mm}$ long. The samples are created by placing a sapphire substrate of dimension $6.35 \mathrm{~mm}$ wide, $31.75 \mathrm{~mm}$ long, and $2.5 \mathrm{~mm}$ thick, in the 4 inch diameter fluidized bed coating furnace along with $109.5 \mathrm{~g}$ of $500 \mu \mathrm{m}$ diameter $\mathrm{ZrO}_{2}$ fuel surrogates.

The preliminary methodology utilized the fluidized bed deposition parameters for the production of TRISO fuel for the Advanced Gas Reactor experiment 1 (AGR-1) fuel. The only difference was that the gas flow rates were scaled up by a factor of 1.5 to account for the amount of argon necessary to fluidize the system in the 4 inch coater (15 liters per minute) versus the 10 liters per minute necessary to fluidize the system in the 2 inch coater. Measurement of density of the first samples produced revealed that the samples had a density of $\sim 1.1 \mathrm{~g} / \mathrm{cm}^{3}$, which is unsuitable for these experiments. The deposition conditions for the fluidized bed were refined to produce pyrocarbon samples with density of $1.9 \pm 0.5 \mathrm{~g} / \mathrm{cm}^{3}$ and Bacon Anisotropy Factor (BAF) range of 1.01-1.03. 
After refining the process for deposition and removal of samples from the sapphire substrates, multiple depositions were performed to begin production of the creep samples. Currently six pyrocarbon samples have been delivered to the University of Michigan for irradiation creep experiments. The first three samples were received in June with another three received in August.

\section{Summary}

A methodology for producing pyrocarbon strip samples has been implemented and is being used to produce a set of samples for proton irradiation induced creep experiments. The results for the pyrocarbon will be compared with the proton irradiation creep results for graphite samples that are nearest to pyrocarbon in microstructure. The first results with the graphite samples show that the transition from primary to secondary creep regime occurs at or below $0.0125 \mathrm{dpa}$, and the linear dependence of creep rate on the applied tensile stress according to the equation:

$$
\dot{\varepsilon}\left(s^{-1}\right)=3.31 \times 10^{-9} \sigma(\mathrm{MPa})+8.08 \times 10^{-9} .
$$

It was also shown that a $24 \mathrm{~h}$ anneal at $900^{\circ} \mathrm{C}$ was sufficient for removing the residual stress remaining from the machining process.

\section{Future Work}

The proton irradiation induced creep experiment will be continued with graphite samples to determine the dose rate and temperature effects on the creep rate. At that point experiments will shift over to pyrocarbon samples. The first dependence that will be studied for pyrocarbon will be the stress dependence, since stress dependence is typically the primary indicator of irradiation creep mechanism in metals. If sufficient samples are available then temperature and dose rate effects will be analyzed. An addendum to this report will be submitted after the proton irradiation induced creep experiments have been performed and analyzed. 
POCO ZXF-5Q, 20MPa, $1000^{\circ} \mathrm{C}, 0.100 \mathrm{dpa} /$ day, 1.213dpa final, Started 11-17-10

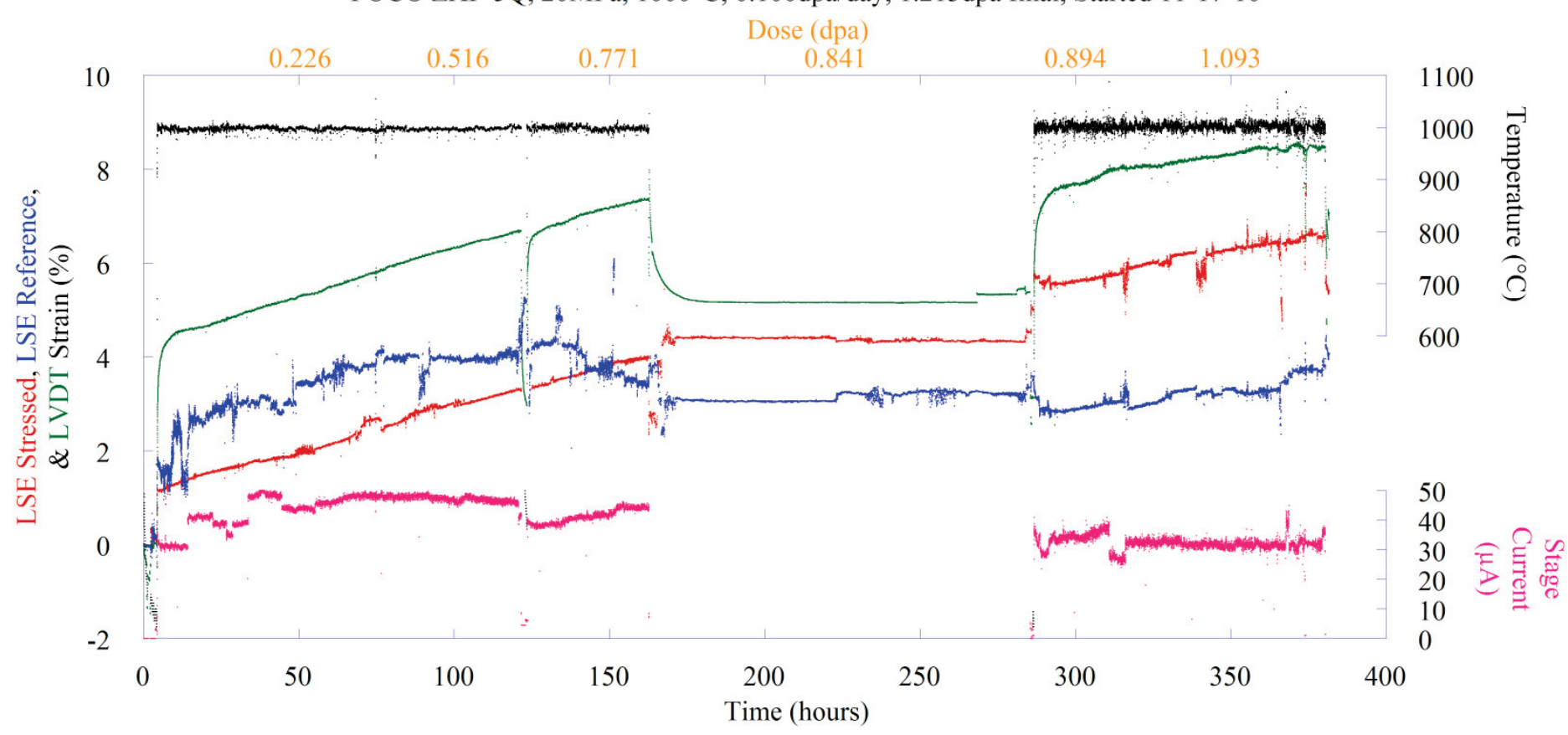

Figure 1. Irradiation creep experiment conducted at $1000^{\circ} \mathrm{C}$ with a stress of $20 \mathrm{MPa}$ and a damage rate of $0.1 \mathrm{dpa} /$ day. Graph shows strain on stress sample measured by LSE (red) strain on reference sample measured by LSE (blue), strain on stress sample measured by LVDT (green), sample temperature (black), and stage current (pink).

Table 1. Summary of the measured creep rate from the LSE and LVDT from the experimental data presented in Figure 1.

\begin{tabular}{|c|c|c|}
\hline $\begin{array}{c}\text { Time Range } \\
\text { (hours) }\end{array}$ & $\begin{array}{c}\text { LSE Creep } \\
\text { Rate }\left(\mathrm{s}^{-1}\right)\end{array}$ & $\begin{array}{c}\text { LVDT Creep } \\
\text { Rate }\left(\mathrm{s}^{-1}\right)\end{array}$ \\
\hline $4.5-162$ & $5.052 \times 10^{-8}$ & $5.645 \times 10^{-8}$ \\
\hline $286-380$ & $3.290 \times 10^{-8}$ & $2.859 \times 10^{-8}$ \\
\hline
\end{tabular}


POCO ZXF-5Q, $20 \mathrm{MPa}, 1000^{\circ} \mathrm{C}, 0.1007 \mathrm{dpa} /$ day, $0.421 \mathrm{dpa}$ final, Started 1-22-11

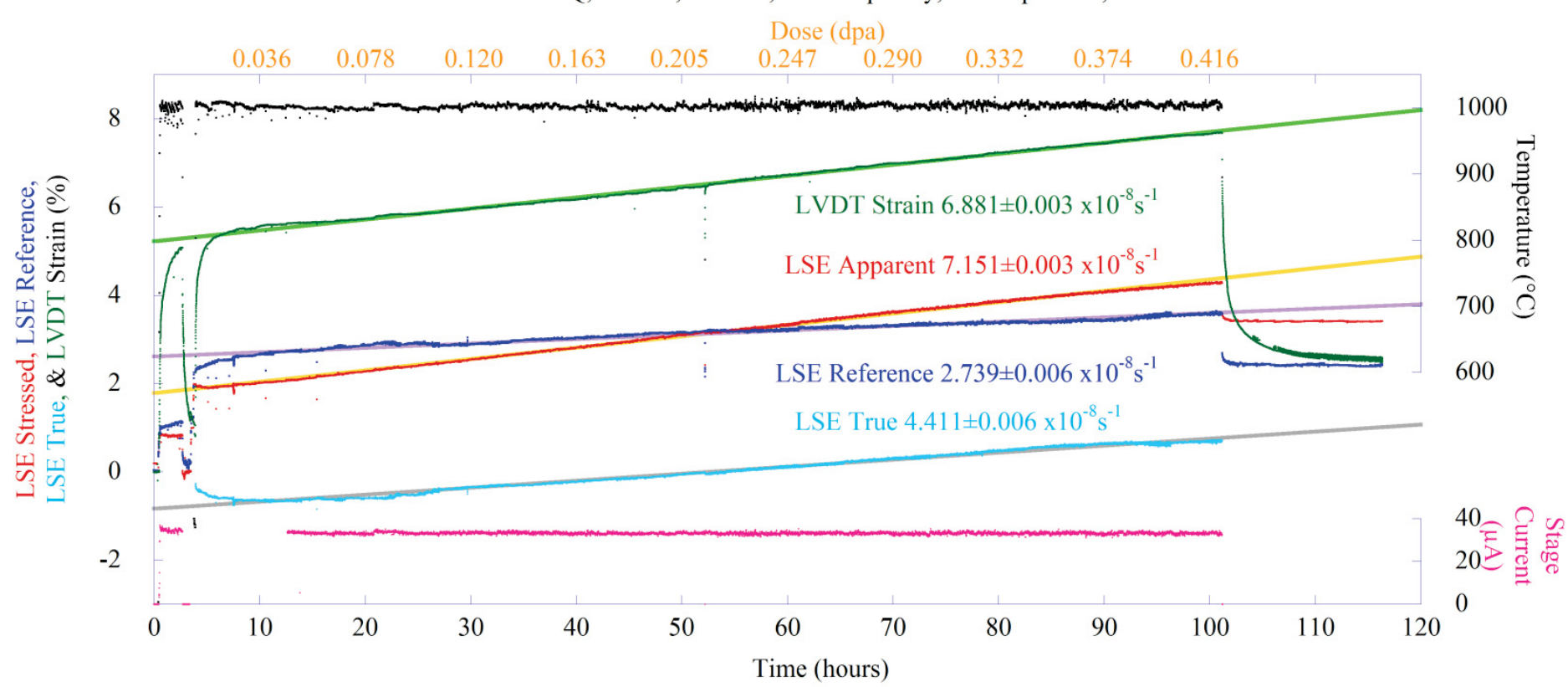

Figure 2. Irradiation creep experiment conducted at $1000^{\circ} \mathrm{C}$ with a stress of $20 \mathrm{MPa}$ and a damage rate of $0.1 \mathrm{dpa} / \mathrm{day}$. Graph shows strain on stress sample measured by LSE (red) strain on reference sample measured by LSE (blue), strain on stress sample measured by LVDT (green), true strain of stress sample (light blue), sample temperature (black), and stage current (pink). 
POCO ZXF-5Q, $40 \mathrm{MPa}, 1000^{\circ} \mathrm{C}, 0.1030 \mathrm{dpa} /$ day, 0.250dpa final, Started 1-29-11

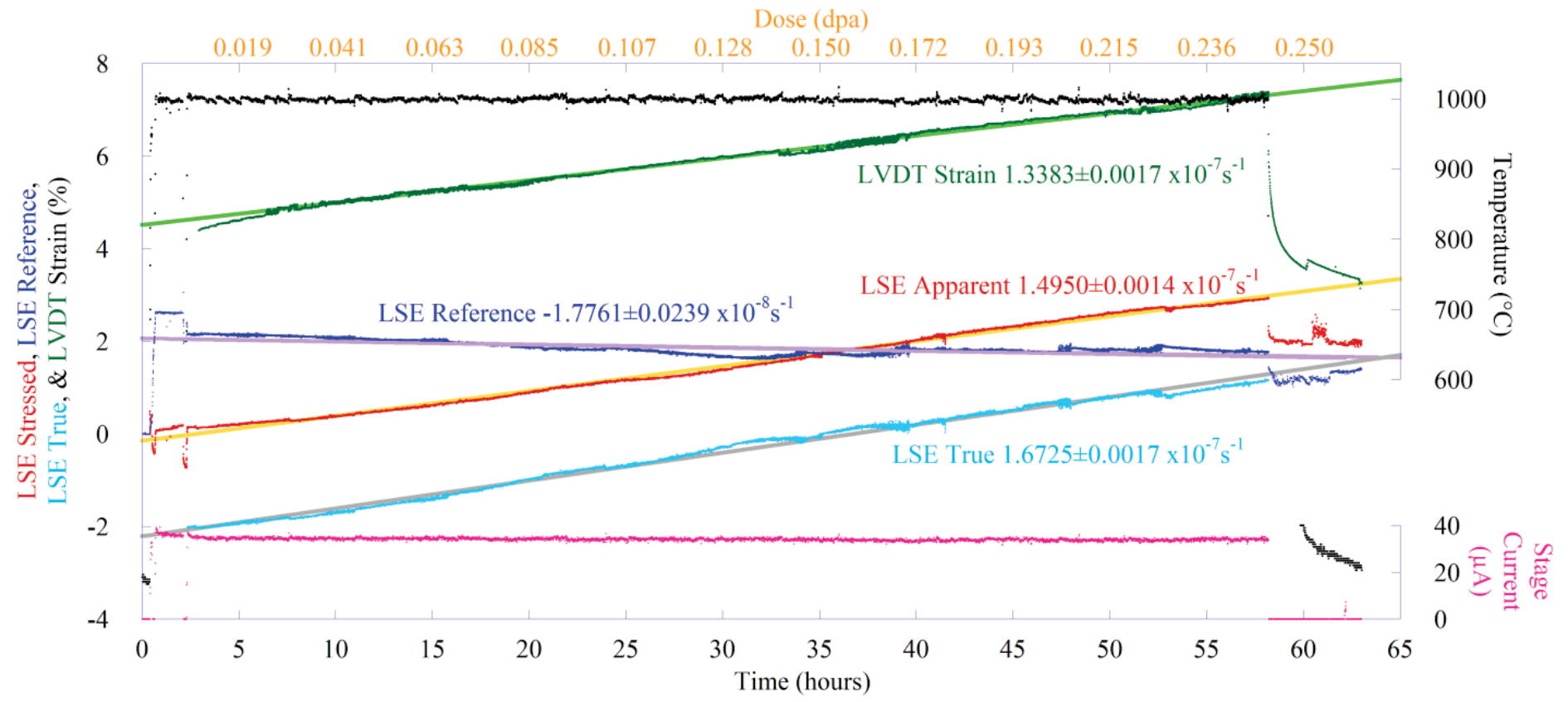

Figure 3. Irradiation creep experiment conducted at $1000^{\circ} \mathrm{C}$ with a stress of $40 \mathrm{MPa}$ and a damage rate of $0.1 \mathrm{dpa} / \mathrm{day}$. Graph shows strain on stress sample measured by LSE (red) strain on reference sample measured by LSE (blue), strain on stress sample measured by LVDT (green), true strain of stress sample (light blue), sample temperature (black), and stage current (pink). 
POCO ZXF-5Q, $10 \mathrm{MPa}, 1000^{\circ} \mathrm{C}, 0.1030 \mathrm{dpa} / \mathrm{day}, 0.212 \mathrm{dpa}$ final, Started 2-3-11

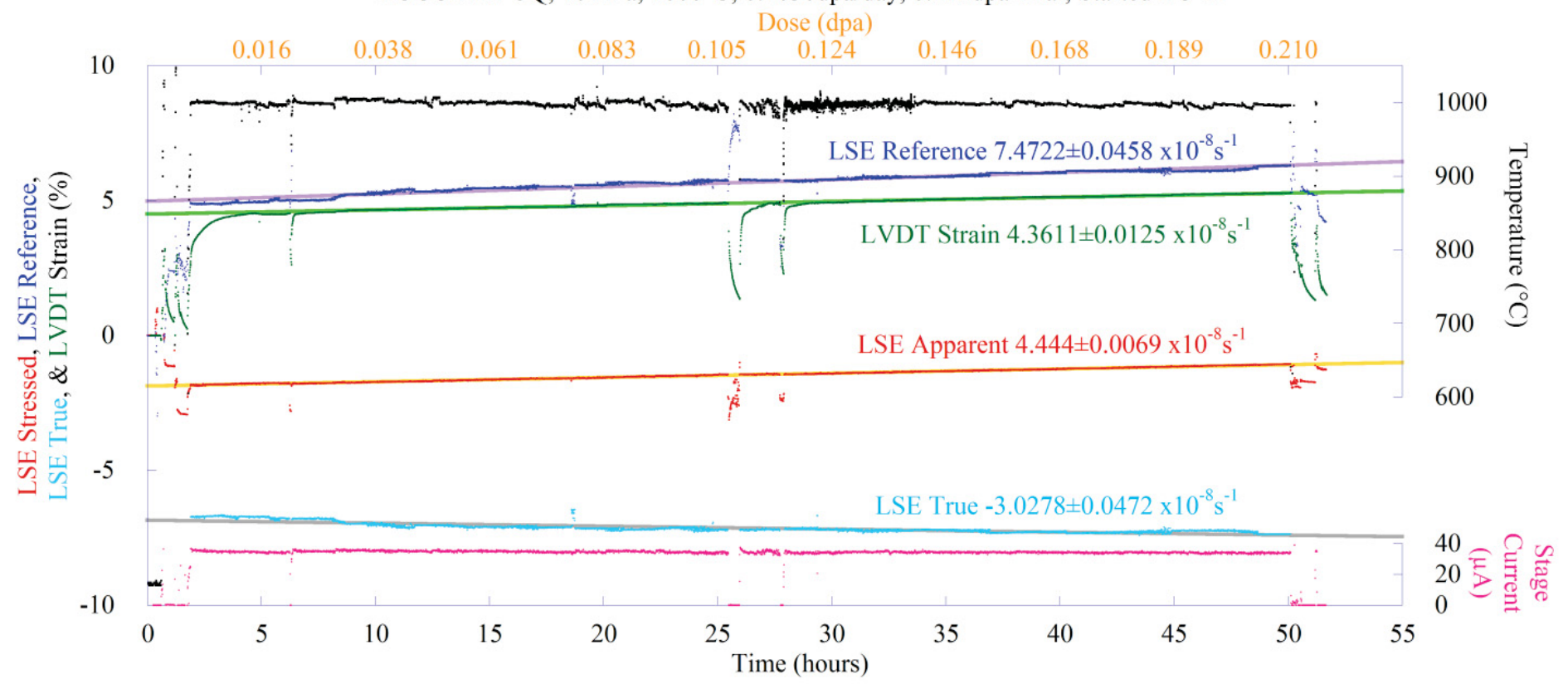

Figure 4. Irradiation creep experiment conducted at $1000^{\circ} \mathrm{C}$ with a stress of $10 \mathrm{MPa}$ and a damage rate of $0.1 \mathrm{dpa} / \mathrm{day}$. Graph shows strain on stress sample measured by LSE (red) strain on reference sample measured by LSE (blue), strain on stress sample measured by LVDT (green), true strain of stress sample (light blue), sample temperature (black), and stage current (pink).

Table 2. Summary of apparent creep rates from the LSE and LVDT for the applied stress used in the analysis in Figure 5

\begin{tabular}{|c|c|c|}
\hline $\begin{array}{c}\text { Applied Stress } \\
(\mathrm{MPa})\end{array}$ & $\begin{array}{c}\text { LSE Apparent } \\
\text { Creep Rate }\left(\mathrm{s}^{-1}\right)\end{array}$ & $\begin{array}{c}\text { LVDT Apparent } \\
\text { Creep Rate }\left(\mathrm{s}^{-1}\right)\end{array}$ \\
\hline 20 (Figure 1) & $5.05 \times 10^{-8}$ & $5.64 \times 10^{-8}$ \\
\hline 20 (Figure 2) & $7.15 \times 10^{-8}$ & $6.88 \times 10^{-8}$ \\
\hline 40 (Figure 3) & $1.50 \times 10^{-7}$ & $1.34 \times 10^{-7}$ \\
\hline 10 (Figure 4) & $4.44 \times 10^{-8}$ & $4.36 \times 10^{-8}$ \\
\hline
\end{tabular}

Table 3. Summary of linear fit of the apparent creep rate versus applied stress.

\begin{tabular}{|l|l|c|}
\hline \multicolumn{1}{|c|}{ Data Used for Fit } & \multicolumn{1}{c|}{ Linear Fit } & \multicolumn{1}{c|}{$\mathrm{R}^{2}$} \\
\hline LSE including data in Figure 1 & $3.72 \times 10^{-9} \sigma-4.50 \times 10^{-9}$ & 0.923 \\
\hline LSE excluding data in Figure 1 & $3.58 \times 10^{-9} \sigma+5.15 \times 10^{-9}$ & 0.993 \\
\hline LVDT including data in Figure 1 & $3.13 \times 10^{-9} \sigma+5.26 \times 10^{-9}$ & 0.960 \\
\hline LVDT excluding data in Figure 1 & $3.05 \times 10^{-9} \sigma+1.1 \times 10^{-8}$ & 0.996 \\
\hline Combined including data in Figure 1 & $3.42 \times 10^{-9} \sigma+3.76 \times 10^{-1}$ & 0.929 \\
\hline Combined excluding data in Figure 1 & $3.31 \times 10^{-9} \sigma+8.08 \times 10^{-9}$ & 0.982 \\
\hline
\end{tabular}




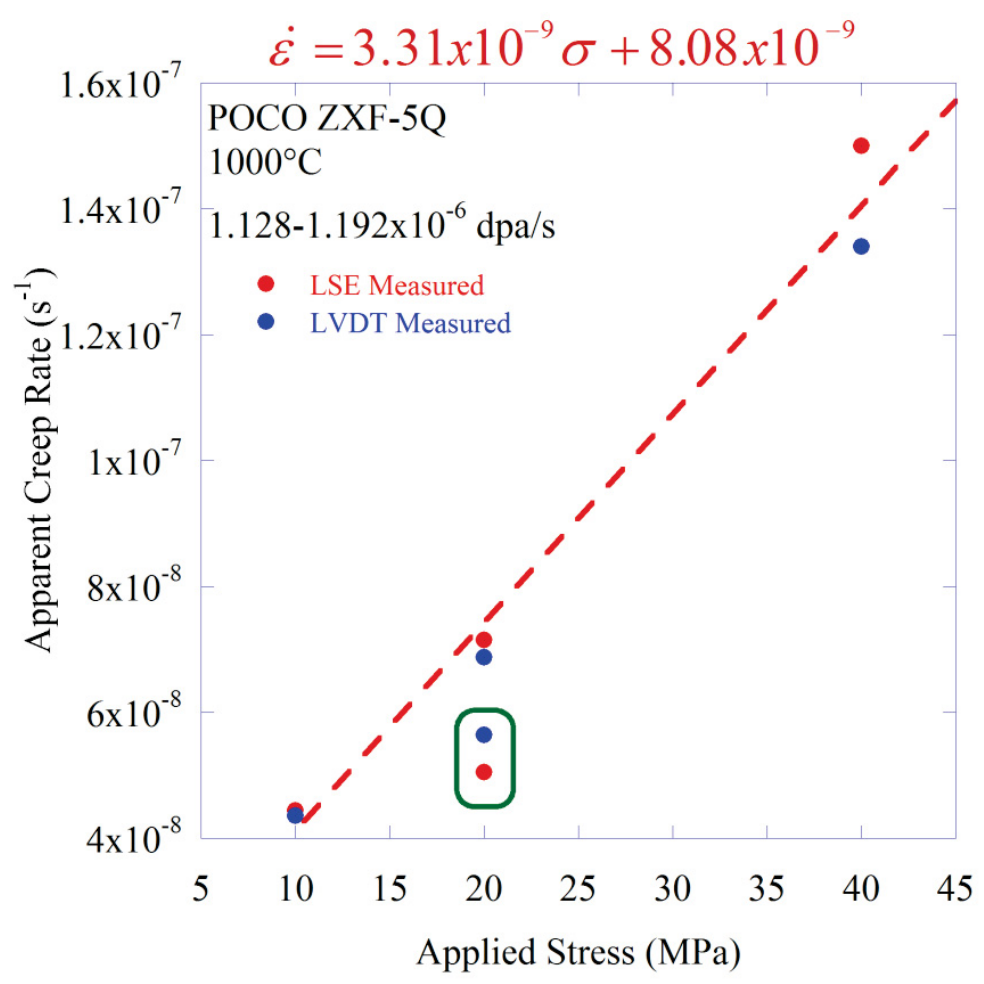

Figure 5. Apparent creep rate measured by LSE (red) and by LVDT (blue) from experiments presented in Figure 1-Figure 4 versus the applied stress. The linear fit shown with the red dashed line is calculated for the combined LSE and LVDT values, without the data from the experiment presented in Figure 1 (circled in green).

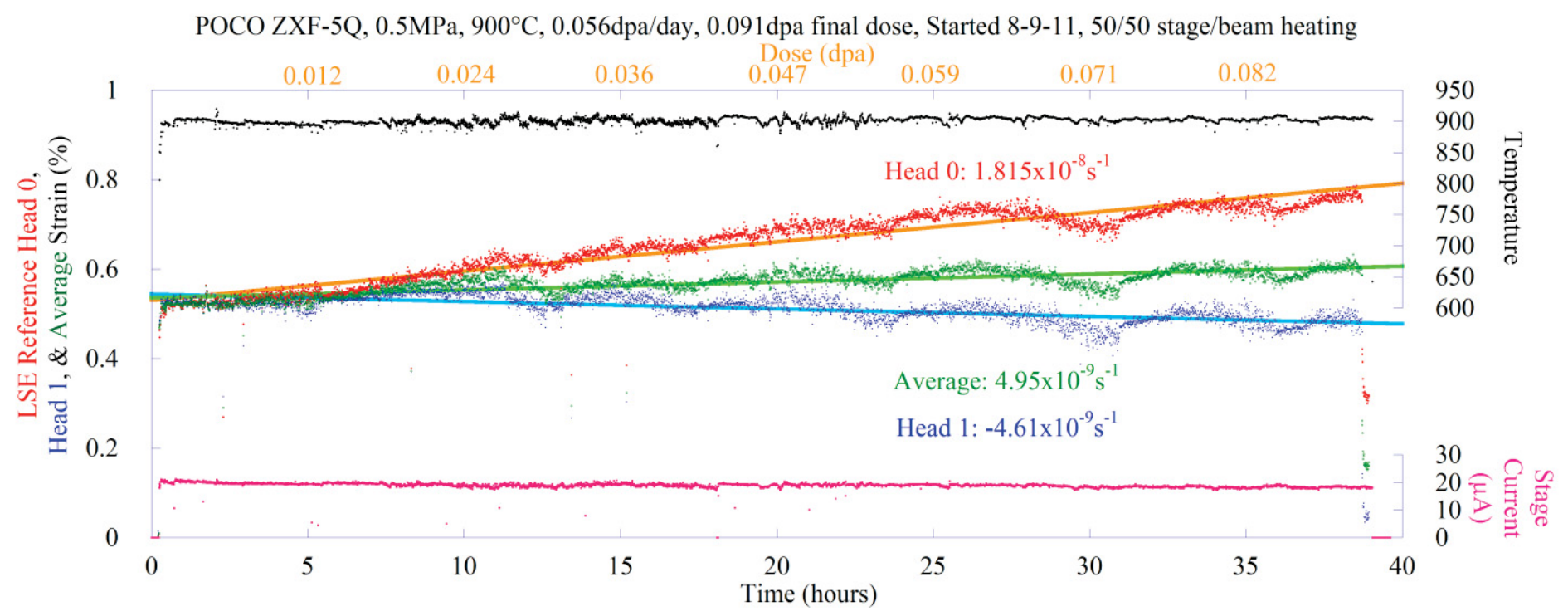

Figure 6. Raw experimental data showing two independent measurements of strain in an annealed, unstressed sample (red and blue) and the average of the two measurements (green), sample temperature (black), and stage current (pink). 


\section{$\underline{\text { References }}$}

1. POCO Graphite Inc., "ZXF-5Q Data Sheet", Accessed on: September 27, 2011, Available from:

http://www.poco.com/MaterialsandServices/Graphite/IndustrialGrades/ZXF5Q/tabid/87/ Default.aspx.

2. Burchell, T.D., "Irradiation induced creep behavior of H-451 graphite", Journal of Nuclear Materials, 381, (2008) 46-54. 